\title{
KERATON KANOMAN DI CIREBON (Sejarah dan Perkembangannya)
}

\author{
KANOMAN PALACE IN CIREBON \\ (ITS HISTORY AND DEVELOPMENT) \\ Oleh Lasmiyati \\ Balai Pelestarian Nilai Budaya Bandung, \\ J1. Cinambo 136 Ujungberung Bandung \\ Email :lasmiyatinizam@gmail.com
}

\begin{abstract}
Abstrak
Keraton merupakan tempat kediaman raja, yang di dalamnya terdapat beberapa bangunan. Di dalam keraton, sultan melaksanakan tugasnya sebagai pemimpin segala kegiatan politik dan sosial budaya. Penelitian ini dilakukan untuk mengetahui bagaimana sejarah terbentuknya Keraton Kanoman di Cirebon dan bagaimana perkembangannya. Metode yang digunakan adalah metode sejarah yang meliputi heuristik, kritik, interpretasi, dan historiografi. Dari hasil penelitian yang dilakukan diperoleh informasi bahwa Keraton Kanoman didirikan tahun 1510 Saka atau 1588 M oleh Pangeran Muhamad Badrudin Kartawidjaja atau Sultan Anom. Mereka menempati bangunan Witana yaitu bangunan yang pertama kali ditempati oleh Pangeran Cakrabuana ketika berada di Tegal Alang-alang. Pangeran Cakrabuana bekerja sebagai penumbuk rebon. Alat yang digunakan adalah lumpang alu dan pencetak terasi. Kedua alat tersebut disimpan di sebuah cungkup. Keraton Kanoman seperti kota tradisional, yang di dalamnya terdapat alun-alun dengan waringin kurung di tengahnya, pasar, masjid agung dan bangunan lainnya. Keraton Kanoman bukan hanya digambarkan sebagai kota tradisional melainkan juga tempat penyelenggaraan upacara Maulid Nabi, yaitu sebuah upacara yang dilakukan untuk memperingati kelahiran Nabi Muhamad SAW.
\end{abstract}

Kata kunci: Keraton kanoman, sejarah dan perkembangan.

\begin{abstract}
Keraton (palace), in which a king lives, comprises several buildings. The Sultan administers every political and cultural activities inside keraton. This research aims to study the history of the establishment of Keraton Kanoman and its development. The methods covered heuristic, critique, interpretation, and historiography. The informant said that the Keraton was established in 1510 Çaka or 1588 AD by Pangeran (Prince) Muhamad Badrudin Kartawidjaja or Sultan Anom. They occupied Witana building which was first occupied by Pangeran Cakrabuana when he was in Tegal Alang-alang. Like other traditional cities, Keraton Kanoman has a plaza inside with a banyan tree in the
\end{abstract}


middle, market, great mosque, and other buildings. The Keraton is not only a traditional city, but it functions as a place to carry out ceremony commemorating the birth of Prophet Muhammad.

Keywords: Keraton Kanoman, history and development.

\section{A. PENDAHULUAN}

Keraton berasal dari bahasa Jawa kuna keratuan dengan kata dasar ratu, mendapat awalan ke dan akhiran an. Kata ratu berarti raja. Kata keratuan menunjukkan keterangan tempat, yaitu sebagai tempat bersemayam raja atau tempat kediaman raja (Tim Peneliti Unpad, 1991: 48-49). Terkait dengan arti keraton, Soeratman mengatakan bahwa keraton merupakan istilah yang mempunyai beberapa arti, pertama berarti negara atau kerajaan dan kedua, sebagai pekarangan raja, meliputi wilayah di dalam Cepuri Baluwerti (Cepuri berarti tembok yang mengelilingi halaman). Baluwerti/Baluarti (bahasa Portugis berarti benteng) atau ditambah dengan alun-alun (Soeratman, 2000: 79). Keraton merupakan kumpulan bangunan tempat bersemayam raja dan keluarganya. Raja sebagai kepala pemerintahan selalu tinggal di dalam keraton yang biasanya dijadikan sebagai pusat kerajaan dan segala kegiatan politik, ekonomi, sosial, dan budaya. Para pejabat tinggi kerajaan dan bangsawan biasanya juga tinggal di sekitar istana. Karena hampir semua kegiatan terpusat di sekitar keraton, maka tempat kediaman raja tersebut kemudian berkembang menjadi kota (Hadimulyono dalam Tim Peneliti Jurusan Sejarah Fak. Sastra Unpad, 1991: 49).

Secara rinci arti keraton adalah:

- Keraton sebagai kerajaan atau negara berarti peran keraton untuk menggarap sisi manusianya. Keraton (keratuan) merupakan tempat sang pemimpin, si pemimpin, sarana penyelenggaraan kepemimpinan. Peran keraton adalah mengembangkan sumber daya manusia.

- Keraton sebagai pekarangan raja, berarti wilayah yang melingkupi tempat bersemayam raja. Peran keraton adalah pemberdayaan dan pengembangan kemampuan manusia berkaitan dengan perbaikan aspek lingkungan sekitarnya. Dalam hal ini termasuk juga pemukiman, perumahan, dan prasarana pendukungnya.

- Keraton sebagai pekarangan/wilayah sampai dengan alun-alunnya, berarti peran keraton mengembangkan budaya dalam kaitannya dengan dunia usaha. Alun-alun merupakan salah satu sarana interaksi antara produsen dan konsumen. Lebih besar lagi adalah keberadaan pasar sebagai tempat bertemunya mekanisme yang menghasilkan (produksi) dan yang menikmati (konsumen). Peran keraton adalah optimalisasi kapasitas manusia dalam hal aspek usaha, lapangan kerja, dan upaya untuk peningkatan pendapatan (Hadisiswaya, 2009: 29).

Bertitik tolak dari pendapat Hadisiswaya, bahwa sebuah keraton selain pekarangan raja yang meliputi wilayah di dalam benteng yang mengelilingi baluwarti, serta pekarangan termasuk alun-alunnya, keraton juga sebagai tempat diselenggarakannya kegiatan budaya serta memiliki kekayaan sejarah dari beberapa bangunan yang ada, sehingga keraton menjadi aset wisata yang dimiliki oleh pemerintah daerah setempat.

Di Cirebon terdapat tiga keraton yang kondisinya masih utuh, yaitu Kasepuhan, Kanoman, dan Kacirebonan. Dari rentetan silsilahnya, ketiga keraton tersebut masih satu keturunan dari Sunan Gunung Jati. Dari ketiga keraton yang ada, penelitian ini akan difokuskan pada Keraton Kanoman. Alasannya, karena Keraton Kanoman masih relatif jarang ditulis, baik di surat kabar maupun bukubuku penelitian, kalau pun ada tulisan 
mengenai Keraton Kanoman hanya mengungkap masalah upacara panjang jimat. Masalah yang diangkat dalam penelitian ini adalah, kapan Keraton Kanoman didirikan dan bagaimana perkembangannya. Tujuan penelitian ini untuk menjawab pertanyaan kapan Keraton Kanoman didirikan dan bagaimana perkembangannya. Metode yang digunakan adalah metode sejarah yang meliputi tahap heuristik, yaitu tahap mencari dan menemukan sumber, baik sumber primer maupun sekunder. Langkah berikutnya melakukan kritik sumber tujuannya untuk mengetahui apakah dari sumber-sumber tersebut valid dan dapat dipercaya. Setelah sumber-sumber dikritik baik ekstern maupun intern, langkah berikutnya mengolah sumber untuk mendapatkan data yang diperlukan. Setelah data terkumpul kemudian diklasifikasi disesuaikan dengan subbab yang akan ditulis. Langkah berikutnya adalah interpretasi, baru kemudian dilakukan penulisan atau historiografi, yaitu merangkaikan fakta hingga menjadi tulisan sejarah.

\section{B. HASIL DAN BAHASAN}

\section{Terbentuknya Keraton Kanoman}

Pada awal abad ke-15, Pangeran Walangsungsang, anak pertama dari Pamanah Rasa (Prabu Siliwangi) dengan Nhay Subanglarang, telah berhasil mengubah pemukiman kecil Tegal Alangalang menjadi pusat nagari dari beberapa desa. Pangeran Walangsungsang memiliki pasukan keamanan keraton, dan menguasai tiga pelabuhan yaitu Muara Jati, Pelabuhan Caruban, dan Jepara. Ia memperoleh pengakuan politik dari Prabu Siliwangi sebagai pemimpin nagari Caruban Larang dan diberi gelar Sri Mangana dan hak otonomi bagi nagari Caruban Larang. Akan tetapi ia tetap harus mengirimkan upeti kepadanya. Tahun 1479, Walangsungsang atau Pangeran Cakrabuana menobatkan Syarif Hidayatullah yaitu anak adiknya (Nhay
Rarasantang yang menikah dengan bangsawan Arab Maulana Sultan Muhamad) menjadi tumenggung. Pengangkatan sebagai tumenggung tersiar hingga Demak. Syarif Hidayatullah diberi gelar oleh para wali di Demak sebagai Panetep Panatagama di Tanah Sunda dengan nama Sunan Gunung Jati. Pada tahun yang sama, ia diundang oleh Sultan Demak yakni Raden Fatah agar membantu pembangunan Masjid Demak yang dikerjakan oleh walisanga (Soenardjo, 1983: 63). Sunan Gunung Jati mendapat bagian membuat soko guru. Soko guru yang berjumlah empat tiang tersebut dikerjakan oleh empat sunan yakni Sunan Gunung Jati, Sunan Kalijaga, Sunan Bonang, dan Sunan Ampel. Selesai membangun Masjid Demak, Sunan Gunung Jati kembali lagi ke Cirebon melanjutkan pekerjaannya sebagai tumenggung dan menjadi waliyullah. Selama memimpin Cirebon, Sunan Gunung Jati meningkatkan pembangunan Nagari Cirebon. Program-program pemerintahan pun berjalan lancar. Ia juga berkeinginan membangun masjid agung Cirebon selayaknya Masjid Demak. Sunan Gunung Jati mengirimkan utusan ke Demak untuk meminta tanggapan kepada Sultan Demak dan para wali akan niat tersebut. Keinginan Sunan Gunung Jati ditanggapi positif oleh Sultan Demak dan para wali. Raden Fatah mengirimkan arsitek terbaik dari Majapahit yakni Raden Sepat yang dibantu oleh Sunan Bonang dan Sunan Kalijaga.

Setelah pembangunan masjid selesai, masjid tersebut diberi nama Masjid Agung Sang Cipta Rasa. Selanjutnya dengan bantuan Raden Sepat pula, Sunan Gunung Jati membuat jalan ke Pasambangan dan memperluas keraton Pakungwati. Dengan demikian maka halhal yang berkaitan dengan pemerintahan dibahas di keraton Pakungwati dan hal-hal yang berhubungan dengan syiar Islam dibahas dan diputuskan di Masjid Agung Cirebon. Pada masa pemerintahan Sunan Gunung Jati, hubungan politik dengan 
Demak semakin baik melalui hubungan keluarga yaitu perkawinan antara putera Sunan Gunung Jati dengan puteri dari Raden Fatah. Ia juga bekerja sama dengan Demak membuat pasukan gabungan Cirebon Demak. Sunan Gunung Jati wafat tahun 1568, posisinya digantikan oleh puteranya yaitu Penembahan Ratu (Soenardjo, 1983: 96).

Ketika Panembahan Ratu naik tahta, Cirebon sudah mencapai kemajuan besar, pemerintahan sudah tertata. Dalam segi perdagangan, Cirebon sudah ramai berkat adanya Pelabuhan Muara Jati. Perdagangan dengan daerah pedalaman berjalan lancar. Cirebon sendiri dikenal sebagai penghasil garam, terasi, dan ikan asin. Dalam segi politik, Panembahan Ratu adalah seorang yang cinta perdamaian, ia sering menjalin hubungan dengan pimpinan kerajaan yang mempunyai misi dalam penyebaran agama Islam. Ia juga menjalin persahabatan dengan kerajaan Mataram di bawah kekuasaan Sultan Agung. Ia menempatkan dirinya secara rendah hati, sehingga Sultan Agung menghargainya sebagai guru. Ia lebih berperilaku sebagai ulama daripada sebagai raja.

Tahun 1645, Sultan Agung digantikan oleh puteranya, Sunan Amangkurat I. Tahun 1649 Panembahan Ratu meninggal dunia. Ia digantikan oleh Pangeran Karim. Pangeran Karim menikah dengan adik Sunan Amangkurat I dan melahirkan 3 orang putera, yaitu Pangeran Kartawidjaja, Martawidjaya, dan Pangeran Wangsakerta. Sunan Amangkurat I mempunyai sifat yang berbeda dengan ayahnya, Sultan Agung. Sunan Amangkurat I lebih bersahabat dengan tentara Belanda. Ia juga memusuhi orang-orang yang tidak mau tunduk kepadanya. Sifat Amangkurat I tersebut dimanfaatkan tentara Belanda untuk mengadu domba, dengan menyebarkan berita bohong kalau Banten akan menyerang Mataram. Percaya akan hasutan Belanda, Sunan Amangkurat I membujuk Pangeran Karim agar menyerang Banten, namun Pangeran Karim tidak menyetujuinya karena Banten masih keturunan kakeknya yaitu Sunan Gunung Jati. Sunan Amangkurat I memanggil Pangeran Karim agar segera ke Mataram. Pangeran Karim memenuhi panggilannya datang ke Mataram beserta kedua puteranya, Pangeran Martawidjaja dan Pangeran Kartawidjaja. Pangeran Karim tinggal di Mataram selama dua belas tahun. Tidak diketahui sebabsebabnya, Pangeran Karim meninggal dunia dan dimakamkan di Bukit Girilaya, terpisah dengan makam raja-raja Mataram Yogyakarta. Sejak itu Pangeran Karim lebih dikenal dengan sebutan Pangeran Girilaya.

Dengan kematian Pangeran Girilaya, di Kesultanan Cirebon terjadi kekosongan kekuasaan. Pangeran Wangsakerta putera ketiga Pangeran Girilaya menghubungi Sultan Banten, agar Sultan Ageng Tirtayasa dapat menemukan kedua saudaranya yang masih berada di Mataram. Oleh karena Cirebon masih saudara dengan Banten, Sultan Ageng Tirtayasa menuju Kediri dengan menumpang kapal perang. Kedatangan ke Kediri bermaksud melakukan persahabatan dengan Trunojoyo dan meminta bantuan kepada Trunojoyo agar dapat membantu melepaskan kedua putera Pangeran Girilaya. Trunojoyo berhasil membebaskan kedua putera Panembahan Girilaya untuk dibawa ke Banten. Kedua putera Pangeran Girilaya kemudian dibawa ke Cirebon. Atas bantuan Sultan Banten dan kerabat Keraton Cirebon lainnya, keraton Pakungwati terpecah menjadi dua yaitu Keraton Kasepuhan dan Keraton Kanoman. Sultan Ageng Tirtayasa kemudian memberikan gelar sultan kepada Pangeran Samsudin Mertawijaya dan menjabat sebagai Sultan Sepuh, dan Pangeran Badrudin Kartawijaya ditunjuk sebagai Sultan Anom. Setelah itu Sultan Badrudin Mertawidjaja dan keluarganya menempati bekas Keraton Pakungwati (sekarang terletak di sebelah timur Keraton Kasepuhan). Sultan Anom (Sultan 
Muhamad Badrudin Kartawidjaja) menempati keraton di bekas rumah pertama Pangeran Cakrabuana ketika baru saja datang ke Tegal Alang-alang atau Kebon Pesisir (Soenardjo, 1983: 153) dengan nama Keraton Kanoman.

\section{Perkembangan \\ a) Keraton Kanoman}

Keraton Kanoman dibangun tahun 1588 M oleh Pangeran Muhamad Badrudin Kertawijaya yang bergelar Sultan Anom I. Ia mendirikan keratonnya di bekas rumah Pangeran Cakrabuana ketika baru saja datang ke Tegal Alangalang bernama Witana (tempat tersebut sekarang masuk ke Kecamatan Lemahwungkuk). Titimangsa tahun berdirinya Keraton Kanoman tertulis dalam sebuah gambar yang ada di Pintu Jinem Keraton Kanoman, yang menggambarkan "matahari" berarti 1, "wayang darma kusuma" yang berarti 5, "bumi" berarti 1, dan "binatang kamangmang" yang berarti 0 . Candrasangkala tersebut menunjukkan angka tahun 1510 Saka atau 1588 M. Jadi Keraton Kanoman didirikan pada tahun 1510 Saka atau 1588 M. Keraton Kanoman dibangun di atas tanah seluas kurang lebih $175.500 \mathrm{~m}^{2}$. Secara administratif, Keraton Kanoman berada di Kelurahan Lemahwungkuk Kecamatan Lemahwungkuk Kota Cirebon. Komplek Keraton Kanoman membujur dari utara ke selatan. Di sebelah utara keraton terdapat alun-alun dan pasar. Sebelah barat laut terdapat masjid Keraton Kanoman, dan di sebelah selatan dan timur berbatasan dengan Sekolah Taman Siswa dan pemukiman penduduk (Hadidjah et al., 2006: 12). Keraton Kanoman dibangun menghadap ke utara, seperti halnya magnet bumi, galaksi, semua menghadap ke utara (wawancara dengan Cheppy tanggal 12 Juni 2012).

Dilihat dari runtutan para sultan yang memerintah Keraton Cirebon, Sultan Badrudin merupakan urutan ketujuh dari Sunan Gunung Jati, yaitu:
1) Sunan Gunung Jati Syech
Hidayahtullah

2) Panembahan Pasarean Muhammad Tajul Arifin

3) Panembahan Sedang Kemuning

4) Panembahan Ratu Cirebon

5) Panembahan Mande Gayem

6) Panembahan Girilaya

7) Sultan Kanoman I (Sultan Badrudin)

Dilihat dari runtutan sultan-sultan Kanoman yang memerintah, maka Sultan Badrudin merupakan sultan pertama yang memerintah Keraton Kanoman.

Ketika menjabat sebagai sultan, Sultan Badrudin mengusulkan agar anak keturunannya tetap menyandang gelar sultan, untuk itu ia meminta persetujuan lebih awal kepada Sultan Ageng Tirtayasa dan Gubernur Jenderal Belanda di Jakarta. Kedua orang itu pun menyetujui keinginan Sultan Badrudin bahwa putera kuturunannya yang menggantikan kedudukannya kelak dapat mengenakan gelar Sultan Anom. Sultan Badrudin mempunyai beberapa putera bernama Pangeran Dipati Madengda, Pangeran Dipati Kedaton, Pangeran Raja Putera, Kanjeng Dipati Awangga, Kanjeng Dipati Ratu, Kanjeng Dipati Pringgabaya, Pangeran Dipati Ratnamanggala, Kanjeng Dipati Keprabon, Dipati Rajakusumah, Jeng Ratu Arya Kidul, Jeng Ratu Arya Wetan, Jeng Ratu Arya Kulon, Jeng Ratu Arya Panengah, Jeng Ratu Arya Lor, Jeng Ratu Arya Kencana, Jeng Ratu Arya Kendar, Ratu Mas Kirana Ayu, Ratu Mas Najiya, Ratu Mas Rara Pawestri (Salana, 1987: 278). Ia memerintah dari tahun 1678 - 1703.

Sultan Badrudin meninggal dunia tahun 1703 dalam usia 99 tahun. Ia digantikan oleh puteranya Pangeran Mandurareja dengan nama Sultan Purudin atau Sultan Khaerudin sebagai Sultan Anom II. Pangeran Mandurareja diangkat sebagai sultan Anom II, ia telah berkeluarga dan mempunyai beberapa putera yaitu Pangeran Gusthi, Pangeran Kresna, Pangeran Winunastra, Ratu Dipati, Ratu Wiyaga, dan Ratu Metasari. 
Sultan Khaerudin menjabat sebagai sultan Anom hanya tiga tahun, karena sakit dan meninggal dunia. Ia memerintah dari tahun 1703-1706, kemudian digantikan oleh puteranya bernama Pangeran Gusthi atau Pangeran Ngalimudin yang bernama Sultan Anom III.

Ketika Sultan Ngalimudin diangkat sebagai sultan Anom III, ia baru berusia 12 tahun, sehingga untuk melaksanakan tugasnya sehari-hari dijalankan oleh wakilnya bernama Pangeran Raja Dipati Kusumaghung atas nama sang Ratu. Setelah Sultan Ngalimudin dewasa, pengambilalihan tahta menjadi sulit, bahkan timbul perselisihan. Kasus ini diadukan kepada Residen Belanda, Komisaris Jogkaginu, dan dinyatakan yang berhak menduduki Sultan Anom adalah Sultan Ngalimudin.

Setelah wafat ia digantikan oleh Sultan Kharidin Rahim sebagai Sultan Anom IV. Ketika Sultan Kharidin Rahim diangkat sebagai sultan ia baru berusia 10 tahun. Demi kelancaran tugas kesultanan diangkatlah wakilnya, yaitu Kiai Tumenggung Bahumadengda. Tumenggung Bahumadengda memerintah dari tahun 1733-1744, namun ketika Sultan Kharidin akan mengambil alih ternyata mengalami kesulitan. Pada saat Sultan Kharidin meninggal dunia, ia meninggalkan banyak putera, baik dari permaisuri atau selir. Perebutan kekuasaan pun tidak dapat dihindari (Salana, 1987: 278). Sultan Raja Alimudin menjabat dari tahun 1744-1798. Setelah wafat ia digantikan oleh Sultan Anom Chaerudin atau Sultan Anom Baberudin dari tahun 1798-1803. Penerus berikutnya adalah Sultan Raja Abo Sholeh Imanuddin atau Sultan Anom Abu Thoyib Imanudin 1803-1811, ia digantikan oleh Sultan Raja Qomarudin I (1811-1858), berikutnya adalah Sultan Raja Qomarudin II (18581873), dilanjutkan oleh Sultan Raja Zulkarnaen (1873-1934). Penerus berikutnya adalah Sultan Raja Nurbuat (1934-1935), dilanjutkan oleh Sultan Raja Muh Nurus (1935-1989), dan digantikan lagi oleh Sultan Raja Muh Djalaludin (1989-2003). Dari tahun 2003 sampai sekarang (2012) yang menjabat sebagai Sultan Anom adalah Sultan Raja Muh Emirudin (sumber: silsilah Sultan Kanoman).

Keraton adalah sebuah lembaga atau institusi yang di dalamnya terdapat struktur organisasi yang terdiri atas raja, patih, dan seterusnya hingga struktur yang paling bawah adalah prajurit atau para abdi dalem.

\section{b) Kota Tradisional}

Keraton Kanoman terdiri atas benteng keraton yang mengelilingi kompleks Keraton Kanoman dan alunalun. Tata letak dasar kota di Jawa digambarkan di pusatnya ada alun-alun yang di tengah-tengahnya terdapat pohon beringin. Rumah sultan berada di sebelah selatan. Di sebelah barat alun-alun terdapat masjid agung (Daldjoeni, 2003:18), perkampungan berada di belakangnya yang disebut kauman. Keraton Kanoman dibangun seperti bangunan kota di Jawa yaitu alun-alun terletak di sebelah utara Keraton Kanoman. Dahulu alun-alun ini berfungsi sebagai tempat dilaksanakannya apel besar prajurit dan kegiatan lainnya. Sekarang alun-alun digunakan sebagai arena publik. Sebutan alun-alun diambil dari kata alun yang artinya ombak. Rakyat yang datang memenuhi tanah lapang di depan istana, terlihat oleh raja dari Siti Inggil bagaikan alun atau ombak (Kunto, 1992/1993: 68).

Di tengah alun-alun terdapat pohon beringin (waringin kinurung). Waringin berarti pohon beringin dan kinurung adalah terkurung. Waringin kinurung berarti pohon beringin yang dikelilingi pagar. Pohon beringin apabila sudah besar, berbatang banyak dan berdaun lebat bisa digunakan untuk berlindung dari gerimis dan teriknya matahari. Pohon beringin mempunyai bentuk seperti payung, merupakan perlambang pengayoman dan keteduhan, dalam hal ini menunjukkan bahwa keraton 
yang dipimpin oleh seorang sultan mempunyai fungsi sebagai pengayom dan pelindung bagi masyarakatnya. Pohon beringin yang menyatu dengan alun-alun juga dapat diartikan sebagai Manunggaling Kawula Gusti yang berarti rakyat dan sultan selalu bersatu. Oleh karena pohon beringin di alun-alun Keraton Kanoman sudah tua, tahun 2010, secara perlahan batang-batangnya patah. Melihat kondisi tersebut Sultan Kanoman mengganti pohon beringin yang sudah rapuh dengan pohon yang baru.

Pendukung sarana kota adalah pasar. Pasar Kanoman terletak di sebelah utara alun-alun. Luasnya $5.450 \mathrm{~m}^{2}$. Pada masa pemerintahan Belanda, Pasar Kanoman diperbaiki dan diperluas. Tahun 1985 pedagang pasar Kanoman mulai menempati lahan milik Keraton Kanoman, dan posisinya mendekati keraton. Mereka beranggapan bahwa dengan mendekati keraton akan mendapatkan berkah (wawancara dengan Ratu Arimbi, 12 Februari 2012). Untuk memberikan kesempatan kepada umat muslim dalam mendekatkan diri kepada Yang Maha Kuasa dibangunlah masjid. Masjid merupakan tempat suci agama Islam yang digunakan untuk melaksanakan salat lima waktu dan tempat mendekatkan diri kepada Tuhan Yang Maha Kuasa, tempat belajar mengaji, memperdalam hafalan Al-Qur'an, dan sebagai tempat syiar agama Islam. Masjid Agung Kanoman terletak di sebelah barat alun-alun menghadap ke timur, beratap tumpang dua dengan puncak masjid berhiaskan mamolo. Lokasi masjid dikelilingi tembok, dengan pintu masuk terletak di sisi timur dan selatan, berdenah bujur sangkar. Saat ini masjid tersebut masih dipergunakan untuk sarana ibadah umat Islam dan tempat penyelenggaraan upacara Maulid Nabi Muhamad SAW. Pada puncak Masjid Agung Kanoman terdapat kubah, di pucuk kubah terdapat mamolo yang melambangkan simbol dari Hindu ke Islam. Saat ini Masjid Agung Kanoman selain dijadikan sebagai tempat ibadah juga berfungsi sebagai tempat pelaksanaan upacara Pelal besar, tawasulan dan marhaban. (wawancara dengan Elang Rahardja, tanggal 13 Februari 2012).

Dalam Kitab Negara Kertagama disebutkan bahwa negara atau negare dapat diartikan sebagai kota yang meliputi keraton dan kompleksnya. Keraton Kanoman terbentuk seperti tata kota tradisional, terdiri atas alun-alun, pasar, masjid agung, dan tempat tinggal sultan. Untuk memisahkan antara tempat tinggal sultan dengan masyarakat, baik itu masyarakat yang menghuni keraton atau pun tidak, mereka dipisahkan dengan benteng. Jadi secara fisik, benteng keraton merupakan pemisah antara keluarga sultan dengan masyarakat. Tata letaknya memanjang dari utara ke selatan. Menurut Tim Peneliti Sejarah Unpad (1991: 50) pembangunan kota yang susunan pusat kotanya meliputi alun-alun, pasar, masjid, dan bangunan sosial lainnya tersebut terjadi pada masuk dan berkembangnya agama Islam. Konsep kota di Jawa yang ada di Keraton Kanoman tersebut diikuti pula oleh beberapa kotakota lainnya seperti Sumedang dan Bandung.

Keraton Kanoman yang dibangun berdasarkan konsep kota tradisional yang meliputi alun-alun, pasar, masjid, dan istana, kawasan tersebut bernama kuthagara. Di kuthagara sultan, yang menempati pusat keraton, dibantu oleh patih atau patih jero yang bertanggung jawab pada masalah perbendaharaan dan keamanan sultan, sedangkan patih jawi yang bertanggung jawab atas jalannya pemerintahan, berada di luar istana bernama negara gung. Wilayah negara gung sebenarnya adalah apanage atau lungguh para bangsawan yang berstatus sebagai patuh (pemilik tanah). Rakyat yang berada di negaragung statusnya sebagai penggarap. Keraton Kanoman mempunyai wilayah-wilayah yang berada di luar Keraton Kanoman seperti Trusmi dan Kasunean. Sebagian masyarakat Trusmi dan Kasunean menggarap tanah- 
tanah milik keraton dan mempunyai hubungan dekat dengan sultan. Wilayah Keraton Kanoman juga meliputi wilayah yang berada di luar kuthagara dan negaragung. Wilayah tersebut bernama mancanegara (Radjiman, 1984: 128). Di wilayah ini tidak terdapat daerah-daerah lungguh. Mereka mempunyai hubungan dekat dengan sultan dan keluarganya. Masyarakat yang menempati wilayah mancanegara pada waktu-waktu tertentu datang menghadap sultan sambil membawa hasil kebun atau pertanian. Waktu-waktu mereka bertemu sultan adalah pada peringatan Maulid Nabi. Saat Keraton Kanoman mengadakan acara Maulid Nabi Muhamad SAW, masyarakat yang berasal dari Majalengka, Kuningan, dan Karawang berdatangan ke Keraton Kanoman, mereka bergotong-royong membantu pelaksanaan acara tersebut. Bentuk gotong royong mereka berkelompok mengerjakan sesuai pekerjaan masing-masing (wawancara dengan Cheppy tanggal 12 Juni 2012).

\section{c) Sultan dan Bangunan Keraton}

Di dalam keraton terdapat beberapa bangunan dengan fungsi yang berbeda-beda. Sultan menempati bangunan bernama Gedung Pedaleman Sultan, yang berfungsi sebagai tempat tinggal sultan dan istrinya. Gedung ini terletak di sebelah timur bangsal kaputran dan bangsal kaputren. Bangsal Kaputren merupakan bangunan yang dihuni oleh puteri-puteri sultan, dan bangsal kaputran yaitu bangsal yang dihuni oleh putera-putera sultan. Bangunan Kaputran terletak di sebelah timur Mande Mastaka sedangkan bangunan Kaputren terletak di sebelah utaranya. Kedua gedung ini dibatasi oleh pagar tembok tinggi.

Raja atau sultan, selain sebagai pemimpin istana, ia dianggap sebagai titisan dewa. Sultan juga mendapat sebutan Panetep Panata Gama atau khalifatullah sebagai wakil Tuhan di dunia. Sultan sebagai keturunan walisanga dapat memberikan pencerahan kepada rakyatnya.
Apa yang dikatakan oleh sultan selalu dituruti. Sultan juga dianggap sebagai Ratu Adil. Ia dapat bertindak adil terhadap rakyatnya. Itu sebabnya sultan sering dimintai pendapat atau nasihatnya. Sultan harus terbuka untuk siapa saja. Sultan mempunyai kekuasaan yang tidak terbatas. Ia harus memberikan perlindungan kepada rakyatnya. Keputusan sultan pun tidak bisa ditentang. Dari hubungan dekat antara sultan dan rakyatnya, perlu adanya sistem keamanan untuk keselamatan sultan dan keluarga. Untuk menjaga keamanan tersebut perlu dipasang sebuah pintu pengaman bernama Pintu Regol Mundu. Pintu ini berdampingan dengan bangsal Singabrata. Pintu ini merupakan pintu bacem karena berfungsi sebagai pengamanan wilayah Keputran dan Keputren. Di sebelah tembok wilayah Kaputran dan Kaputren terdapat pintu gerbang berbentuk candi bentar yang menghubungkan antara wilayah Kaputran dan Kaputren dengan Gedung Pedaleman Sultan.

Selain membangun gedung untuk tempat tinggal, sultan juga membangun taman bernama Taman Kebon Raja. Taman Kebon Raja merupakan taman penyegar suasana yang berada di sebelah barat Mande Mastaka. Berdekatan dengan Gedung Pedaleman Sultan, Bangsal Kaputran, dan Bangsal Kaputren terdapat Kebon Jimat berfungsi sebagai pungkuran keraton. Kebon Jimat merupakan gedung yang di dalamnya terdapat beberapa sumur keramat (sumur pitu), yaitu Sumur Bandung yang berukuran paling besar, Sumur Panganten yang berbentuk bujur sangkar, Sumur Kajayaan yang berbentuk bundar, dan Sumur Agung Witana yang berbentuk bundar dan dihiasi wadasan. Tidak jauh dari sumur kajayaan, terdapat bangunan tinggi (dua lantai) yang digunakan untuk menyimpan barang jimat keraton bernama Bangsal Pejimatan. Dulu tempat ini sebagai tempat pemburatan yaitu tempat membuat boreh dan jamu untuk sarana upacara Maulid Nabi 
(wawancara dengan Elang Raharda tanggal 13 Februari 2012).

Sultan juga berhubungan dekat dengan para pejabat keraton. Apabila para pejabat keraton akan menghadap sultan, terlebih dahulu akan menunggu di sebuah bangsal bernama Bangsal Singabrata. Bangsal ini terletak di sebelah gedung museum dengan konstruksi bangunan malang semirang. Singabrata berarti singa besar yaitu sebagai tempat para penggede keraton menunggu sebelum menghadap sultan. Tamu yang memerlukan tempat parkir, kendaraannya dapat diparkir di Blandongan Jinem. Blandongan ini terletak di depan Bangsal Jinem berbentuk bujur sangkar. Blandongan Jinem berfungsi sebagai tempat parkir kendaraan para tamu, pejabat, dan lain-lain yang hendak bertemu sultan. Setelah dapat menghadap sultan, tamu tersebut ditempatkan di Bangsal Jinem. Bangsal ini terletak di sebelah selatan Blandongan Jinem. Konstruksi bangunannya berbentuk malang semirang (joglo berganda). Bangsal Jinem berfungsi untuk menerima tamu, baik dari masyarakat atau pun pejabat yang ingin menghadap sultan atau menghadiri undangan dari sultan. Nama Jinem diambil dari kata $j i$ adalah terpuji, nem adalah mufakat atau perkataan. Pendopo ini disangga dengan lima pasang tiang besar, melambangkan shalat lima waktu, juga disangga dengan dua puluh tiang kecil melambangkan sifat-sifat Allah yang berjumlah 20 (wawancara dengan Elang Rahardja, 13 Februari 2012).

Di belakang Bangsal Jinem terdapat ruang Prabayaksa. Dahulu ruang Prabayaksa dijadikan tempat penyelenggaraan upacara seperti Mauludan, ulang tahun Cirebon, maupun penobatan raja. Di belakang ruang Prabayaksa terdapat ruang kecil bernama Mande Mastaka. Mande Mastaka terletak di sebelah selatan bangsal Jinem. Bangunan ini berdampingan dengan Bangsal Jinem hanya disekat tembok dan tiga buah pintu. Konstruksi bangunan beratap joglo dengan hiasan dan ornamen di atas plafonnya terdapat ukiran kayu. Mande Mastaka berfungsi untuk menerima para undangan, seperti pada peringatan Maulid Nabi dan acara pagelaran kesenian tarian bedaya. Mande Mastaka juga difungsikan sebagai Mande Pelayonan yaitu untuk menempatkan jenazah sultan dan keluarga untuk disalatkan. Pada plafon Mande Mastaka yang berukir terdapat angka tahun pembuatan bangunan. Tetapi sayang angka tahun tersebut tidak bisa dibaca karena bentuk hurufnya sudah kusam. Akan tetapi candra sengkala yang berada di pintu utama pembatas antara Bangsal Jinem dan Mande Mastaka masih dapat dibaca. Candra sangkala tersebut berupa ukiran di daun pintu yang berbunyi kemangmang ing bumi pandawa surya atau bisa dibaca kemangmang ing bumi pandawa candra yang menunjukkan angka tahun 1510 Saka atau 1588 Masehi.

Di dalam Mande Mastaka terdapat kursi gading yang dikeluarkan hanya setahun sekali, di atasnya terdapat ukiran tatrap yang berarti sukses, maknanya bahwa dahulu bagi siapa yang masuk ke ruangan ini akan sukses, segala apa yang dicita-citakan akan berhasil. Di belakang Mande Mastaka terdapat hiasan wadasan dan megamendung. Wadasan berasal dari kata wadas yang berarti karang yaitu perwujudan dari batu karang. Megamendung berasal dari kata mega atau awan dan mendung (hitam) bermakna awan hitam yang mendatangkan hujan (Yayasan Mitra Budaya Indonesia, 1982: 148-149). Bangunan tersebut juga dihiasi dengan piring keramik dari Belanda. Piring keramik Belanda yang menghiasai bangunan Mande Mastaka tersebut menandakan bahwa dahulu Sultan Kanoman pernah menjalin hubungan persahabatan dengan pemerintah Belanda. Piring keramik tersebut ada yang merupakan hadiah dari Gubernur Jenderal Belanda dan ada pula yang segaja ditinggal disebabkan kekalahannya terhadap pemerintahan Jepang, sehingga tentara Belanda meninggalkan Cirebon tanpa membawa piring keramik tersebut. 


\section{d) Peninggalan leluhur Cirebon}

\section{1) Lumpang Alu}

Lumpang Alu ditempatkan di dalam bangunan terbuka di komplek Keraton Kanoman bagian depan, bangunan tersebut berukuran $0,7 \times 1 \times 1,5 \mathrm{~m}$, terbuat dari bahan kayu, atap genting disangga dengan empat tiang, bangunan tersebut bernama Cungkup Alu. Menurut Elang Rahardja, lumpang alu inilah yang digunakan oleh Pangeran Walangsungsang/Cakrabuana menumbuk rebon untuk dijadikan terasi dan petis. Lumpang alu dianggap benda bersejarah keraton, karena alat tersebut pernah digunakan oleh Pangeran Cakrabuana. dengan perantara alat ini pula Kampung Tegal Alang-alang menjadi kampung yang ramai didatangi orang untuk memesan terasi dan petis. (wawancara dengan Elang Rahardja, 13 Februari 2012).

\section{Pangeran Cakrabuana} merupakan leluhur para sultan di Keraton Kanoman. Pangeran Cakrabuana adalah putera Prabu Siliwangi yang menikah dengan Nyi Subanglarang. Dari pernikahannya lahirlah Pangeran Walangsungsang yang kemudian bergelar Pangeran Cakrabuana, Nyi Rarasantang, dan Pangeran Sengara. Pangeran Walangsungsang dan adiknya Nyi Rarasantang meninggalkan istana untuk belajar agama Islam. Sesampainya di kediaman Ki Danuwarsih Pangeran Walangsungsang berjodoh dengan Nyi Indang Geulis. Mereka bertiga kemudian melanjutkan perjalanannya ke arah pesisir, yaitu ke Pasambangan di Nagari Singapura (nagari asal ibunya). Di sana mereka berguru agama Islam kepada Syekh Datuk Kahfi selama 3 tahun. Setelah tamat mereka diperintahkan oleh gurunya untuk mendirikan pendukuhan di Kebon Pesisir, yang waktu itu berada di sebuah Tegal Alang-alang, letaknya di tepi pantai sebelah timur Pasambangan, atau kurang lebih $6 \mathrm{~km}$ dari Pasambangan, yang kemudian dijadikan sebagai tempat tinggalnya. Di Kebon Pesisir telah menetap lima orang penduduk yaitu Ki Danusela atau $\mathrm{Ki}$ Gedeng Alang-alang disertai isterinya Nyai Arumsari dan puterinya Nyai Ratnariris dan ditemani oleh abdinya sepasang suami isteri (Iskandar, 2000: 78). Wilayah Kebon Pesisir inilah yang kemudian dijadikan pemukiman baru yang kemudian bernama Cirebon Pasisir ${ }^{1}$. Mereka mulai membuka hutan di Tegal Alang-alang, yang waktu itu masih berupa hutan belantara. Di Pedukuhan tersebut, Pangeran Walangsungsang beserta istri dan adiknya menyamar sebagai rakyat biasa. Tidak jauh dari tempat tinggal mereka terdapat sungai yang banyak rebonnya (udang kecil). Rebon yang didapatkan dari sungai, mereka tumbuk menggunakan lumpang batu dan hulu batu, oleh mereka rebon tersebut dibuat terasi. Kegiatan Walangsungsang dan keluarga diikuti oleh masyarakat sekitarnya. Kegiatan menumbuk rebon dilakukan pada malam hari sebelum tidur. Akhirnya mereka dapat menghasilkan terasi dan petis yang disukai masyarakat di sekitar Kampung Tegal Alang-alang, sejak itu Kampung Tegal Alang-alang menjadi daerah penghasil rebon.

Berkat ketekunannya, Kebon Pesisir yang semula berupa hutan belantara berubah menjadi pedukuhan, yang semakin hari semakin ramai. Masyarakat dari luar Kampung Tegal Alang-alang berdatangan untuk memesan terasi dan petis tersebut, sehingga Kampung Tegal Alang-alang menjadi terkenal sebagai daerah penghasil terasi dan petis yang sangat enak. Banyak penduduk dari berbagai negeri seperti bangsa Cina dan bangsa lainnya berdatangan ke tempat ini, Seketika itu pula wilayah Caruban menjadi wilayah yang sangat ramai, banyak kapal yang singgah di Muara Jati. Oleh karena masyarakat dari berbagai daerah berbaur di tempat ini maka tempat tersebut diberi

\footnotetext{
${ }^{1}$ Saat ini tempat tersebut bernama

Lemahwungkuk kelurahan Lemahwungkuk Kota Cirebon.
} 
nama Caruban yang diambil dari kata campuran, Berita tersebut didengar oleh Raja Galuh Prabu Cakraningrat dan patihnya, Adipati Kiban. Raja Galuh

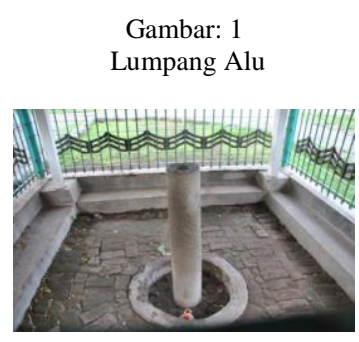

Alat pencetak terasi

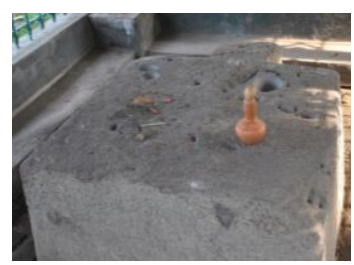

Sumber: Penelitian 2012

memerintahkan kepada Adipati Palimanan untuk mengadakan penyelidikan. Dari hasil penyelidikan yang dilakukan tenyata di daerah pantai Tegal Alang-alang ada penangkapan dan penumbukan rebon yang kemudian dibuat terasi. Cara membuat terasi, terlebih dahulu rebon ditumbuk kemudian dicetak dengan pencetak terasi.

Ketika Pangeran Walangsungsang beserta istri dan adiknya sedang membuat terasi menggunakan lumpang alu, secara kebetulan pejabat dari Galuh melihat masyarakat mengantri untuk membeli terasi tersebut. Dengan rasa penasaran Mantri Pepitu dari Galuh menanyakan proses permbuatan terasi tersebut. Raden Walangsungsang dibantu oleh Rarasantang menerangkan proses pembuatan terasi dan petis, bahwa petis dibuat dari perasan rebon yang telah dimasak dan kemudian dimasak lagi dengan diberi bumbu-bumbu secukupnya. Ketika Mantri Pepitu melakukan kunjungannya, mereka pun disuguhi hidangan petis sebagai lauk- pauknya. Menurutnya, petis jenis blendrang rasanya lebih enak dibandingkan dengan garage dan terasinya (Rochani, 2008: 74-75). Tujuh mantri utusan Adipati Kiban kemudian menyampaikan pesan kepada Pangeran Walangsungsang, bahwa Raja Galuh mengharapkan setoran pajak dan upeti sebesar satu pikul rebon halus per tahun, dan harus disetorkan ke Raja Galuh.

Pernyataan tersebut sesuai dengan Babad Tanah Sunda Babad Cirebon yang mengatakan:

Kocapa Cakrabumi sinareng kang garwa tuwin kang rayi lagi bebek rebon rebut dingin, tumpang tindih, wong gunung pating carowet: "Oga ae, geura age, geura bebek". Dadi misuwur tanah Grage, yang artinya: Diceritakan Cakrabumi bersama sang isteri dan sang adik sedang menumbuk rebon di lumpang batu dengan halu batu. Orang yang mengkulak rebon berebut saling mendahului berdesak-desak sambil berceloteh. "Oga. age, geura age, geura bebek". (cepat-cepatlah ditumbuk). Jadi masyur pedukuhan baru itu disebut nama Grage (Sulendraningrat, 1982: 13).

Pada kesempatan tersebut, para mantri Pepitu mengumpulkan masyarakat sekitar untuk meresmikan nama kampung baru tersebut menjadi Kampung Cirebon.

\section{2) Bangsal Witana}

Bangsal Witana merupakan bangsal peninggalan Ki Gedeng Alangalang. Bangsal ini terletak di areal Keraton Kanoman paling belakang, tepatnya sebelah barat Kebon Jimat. Nama Witana berasal dari kata wiwit ana yang mengandung arti pertama kali ada rumah. Bangsal Witana adalah bekas rumah tinggal Ki Gedeng Tegal Alang-alang yang menjadi kuwu Cirebon pertama. Ki Gedeng Alang-alang membangun rumah tersebut pada abad ke-14 dengan bentuk bangunan joglo yang disangga dengan 4 (empat) tiang yang melambangkan empat kelima pancer. Arti empat kelima pancer yaitu 


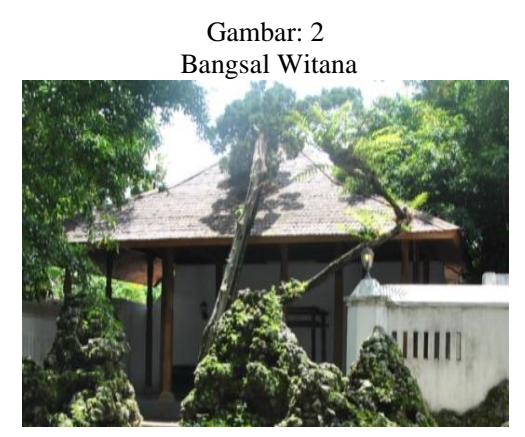

Sumber: Penelitian 2011

sebagai gambaran empat malaikat Jibril, Mikail, Izrail, Isrofil, dan empat sahabat Nabi yaitu Abubakar, Umar, Usman, dan Sayidina Ali. Dalam setiap tiangnya terdapat ukiran berbentuk teratai dan kembang wijayakusumah. Kembang teratai melambangkan kemandirian hidup, artinya jangan sampai mengandalkan orang lain, harus mandiri, dan hanya menyerahkan diri kepada Tuhan Yang Maha Kuasa, karena Tuhan Maha Pengasih dan Maha Penyayang. Kembang Wijayakusumah mengandung arti harus mandiri jangan sampai merepotkan orang lain.

Di bagian atap Bangsal Witana terdapat lambang matahari, yang mengandung filosofi bahwa matahari dapat menerangi dunia. Makna di sini bahwa keraton sebagai basis syiar Islam dapat memberikan penerang kepada masyarakat Cirebon. Lambang matahari memberikan simbol penerang dari masa kebodohan ke arah peralihan, dari masa Hindu ke masa Islam. Selain itu terdapat lambang naga kamangmang berkula api, artinya bahwa hidup harus serius dan berpikir lebih maju. Di atas api ada burung, artinya harus berpikir lebih tinggi, pintar, menyeluruh. Burung akan selalu waspada dan berpikir luas. Di bagian depan sebelah kanan pada bangunan Witana terdapat pohon dewandaru yang menggambarkan masa peralihan dari Hindu ke Islam. Pohon ini ditanam pada abad ke-12. Di sebelah samping kiri bangunan Witana terdapat musala dan kolam yang digunakan untuk berwudu.
Di halaman bangsal Witana terdapat dua buah hiasan berupa benda yang kokoh berukir bernama wadasan dan mega mendung yang melambangkan sebagai manusia harus berpendirian kuat, tegas, dan kuat dalam menghadapi tantangan. Hiasan mega mendung dan wadasan tersebut sering ditemukan dalam corak batik Cirebon. Motif wadasan ditemukan oleh Pangeran Cakrabuana, sedangkan motif mega mendung ditemukan oleh Sunan Gunung Jati. Di sebelah kiri bagian depan Bangsal Witana terdapat gapura yang melambangkan dua kalimah syahadat. Di sebelah kanan gapura terdapat menara. Pada abad ke-15, menara tersebut digunakan untuk melihat hamparan laut, pantai, dan kapal-kapal yang bersandar di pelabuhan Cirebon, disebabkan letak Bangsal Witana dan laut Cirebon hanya berjarak kurang lebih 500 $\mathrm{m}$. Menara tersebut juga dijadikan sebagai tempat mengintai apabila ada musuh yang datang. Seiring perjalanan waktu laut Cirebon mengalami abrasi, hamparan laut sudah tidak kelihatan. Di sebelah kanan pelataran bangunan Witana terdapat sumur Witana. Sumur tersebut dibangun pada zaman kasultanan. Di depan bangsal Witana terdapat pasolatan yang di masa lalu digunakan sebagai tempat salat.

Pada saat ini Bangsal Witana digunakan sebagai tempat peringatan ulang tahun Cirebon yang jatuh setiap tanggal satu Muharam.

\section{e). Bangunan Lainnya}

Keraton Kanoman selain dilengkapi dengan bangunan pedaleman yang dihuni oleh sultan bersama keluarganya, juga dilengkapi dengan tempat penerimaan tamu, tempat kegiatan atau upacara adat keraton, dan bangunan lainnya. Bangunan lain yang ada di Keraton Kanoman adalah: Bangunan Kompleks Siti Inggil. Komplek Siti Inggil dinamakan lemah duwur atau tanah tinggi, karena keadaan tanahnya lebih tinggi dibandingkan dengan keadaan tanah pada bangunan lainnya. Kompleks Siti Inggil 


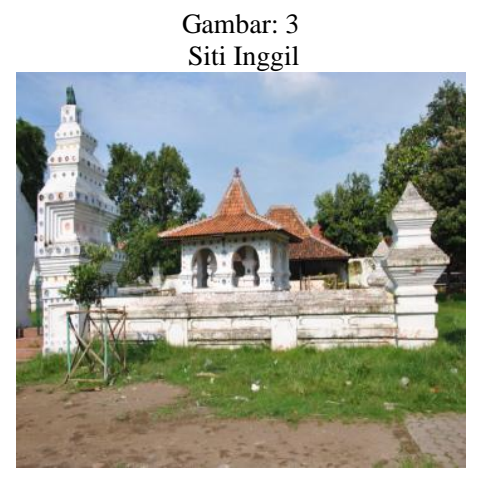

dipagar (dibenteng tembok) setinggi 1,30 m. Untuk masuk ke kompleks Siti Inggil harus melewati:

- pintu syahadatein, yaitu pintu masukyang menghadap utara;

- pintu kiblat, yaitu pintu yang menghadap barat;

- pintu sholawat, yaitu pintu masuk yang menghadap ke selatan.

Komplek Siti Inggil mempunyai makna filosofi: "Apabila seorang ingin mencapai derajat yang tinggi, maka harus membaca syahadatain sebagai syarat muslim, menghadap kiblat dengan melakukan shalat sebagai salah satu kewajiban muslim, dan senantiasa bershalawat serta melaksanakan sunnahsunnah Nabi Muhamad SAW sebagai pemimpin muslim".

Di dalam kompleks Siti Inggil terdapat 2 bangunan, yaitu: Mande Manguntur dan Bangsal Sekaten. Mande Manguntur menghadap ke utara, berukuran $6,5 \times 6,5 \times 5 \mathrm{~m}$, tiang terbuat dari bahan bata, berlantai keramik, berundak dua. Bangunan ini terbuka tanpa dinding, dari tiang satu ke tiang lainnya saling berhubungan, melengkung menyerupai gerbang, beratap genting berbentuk kerucut. Di dalamnya terdapat balai berukuran $1,50 \times 1,50 \mathrm{~m}$ untuk tempat duduk Sultan. Secara keseluruhan bangunan ini diperindah dengan hiasan piring keramik yang ditempelkan di tiang dan dinding tembok. Keramik yang menempel pada tembok bangunan Siti Inggil berasal dari Dinasti Ming. Mande Manguntur berfungsi sebagai tempat palinggihan sultan sewaktu menghadiri dan menyaksikan upacara sakral seperti apel prajurit, pemukulan perdana gamelan sekaten setiap tanggal 8 Maulud. Balai ini juga digunakan sultan untuk menyampaikan berita atau pun wejangan, hukum, aturan agama kepada masyarakat. Bangunan kedua bernama Bangsal Sekaten. Bangsal ini dibangun di sebelah Mande Manguntur, berfungsi khusus untuk pementasan gamelan sekaten yang dilaksanakan setiap tanggal 8 sampai dengan 12 Maulud. Bangunan ini dibangun dengan konstruksi malang semirang dengan tujuan memiliki rongga resonansi sehingga apabila gamelan dibunyikan mempunyai suara gema yang khas. Porselen yang menempel di dinding atau pun pintu gerbang Siti Inggil berasal dari Cina. Porselen tersebut berada di Cirebon disebabkan adanya hubungan baik antara Kasultanan Cirebon dengan bangsa Cina. Di Cirebon, bangsa Cina berdagang sambil memperdalam agama Islam. Ketika mereka berdagang, salah satu barang yang dijual adalah porselen. Namun ada pula yang berpendapat bahwa porselen Cina tersebut dibawa oleh istri Sunan Gunung Jati, Ong Tien Nio ke Cirebon (wawancara dengan Elang Rahardja, 13 Februari 2012).

Bangunan lainnya yaitu: Bale Paseban dan Gerbang Seblawong. Balai Paseban dibangun di sebelah selatan Kompleks Siti Inggil. Balai ini berukuran $12 \times 12 \times 4$ m, menghadap ke barat, bahan bangunan menggunakan kayu dengan lantai tegel. Bentuk bangunan beratap malang semirang, ruangan terbuka tanpa dinding, tiang-tiangnya menopang atap sirap limasan, dari tiang satu ke tiang lainnya dipasang penghalang berbentuk pagar kayu. Bangunan ini berfungsi untuk tempat tunggu antrian (giliran) menghadap sultan, tepak seba masyarakat, pejabat serta jajaran kesultanan yang ingin menghadap dan bertemu dengan sultan. Bangunan ini juga digunakan untuk Upacara Buang Takir dan Selamatan Bubur Sura. 
Seblawong berarti besar dan tinggi, yaitu pintu gerbang besar dan tinggi. Bangunan tersebut berdampingan dengan Komplek Siti Inggil. Daun pintu yang digunakan kayu jati yang besar dan tebal, gerbangnya terbuat dari bata berbentuk paduraksa dengan tinggi $9 \mathrm{~m}$, lebar 4,80 m dan tebal $2 \mathrm{~m}$. Bangunan ini tampak kokoh bergaya bangunan kolonial, memiliki ragam hias tiang-tiang samara dengan pelipit vertikal dan horizontal. Di tengahnya dihubungkan dengan pelipit vertikal yang melengkung. Pada bangunan dihias piring keramik porselen yang ditempel pada seluruh permukaan pintu gerbang. Pintu gerbang ini dibuka pada waktu perayaan Maulid Nabi Muhammad SAW.

Pintu/Kori Kejaksan terletak di sebelah selatan Balai Paseban. Pintu ini berbentuk pintu regol atau gledegan digunakan oleh sultan ketika memasuki Balai Paseban untuk membicarakan masalah-masalah hukum, agama, dan lainlain. Di sebelah barat pintu Seblawong adalah Taman Balong Asem. Dinamakan Balong Asem karena terdapat kolam/balong dan pohon asem, Taman Balong Asem dihiasi dengan patung berbagai jenis binatang satwa seperti gajah, kijang, dan macan singa barong. Selain itu juga terdapat bangsal Singabrata. Konstruksi bangunan Bangsal Singabrata malang semirang. Sesuai namanya Singabrata yang berarti singa besar, yaitu sebagai tempat para penggede keraton menunggu sebelum menghadap sultan. Nama semirang diambil dari kata seni dan mengarang yang artinya berseni/berkarya. Bangunan tersebut berfungsi sebagai tempat berkumpulnya para seniman dan budaya untuk mencari inspirasi dan tempat berdiskusi para seniman. Bangunan ini terletak di sebelah barat Kebun Raja yang penuh dengan ornamen dan hiasan taman, seperti wadasan dan mega mendung.

Untuk melaksanakan rangkaian upacara Maulid Nabi juga mengambil tempat di langgar keraton. Langgar Keraton terletak di sebelah barat pintu
Regol Kejaksan, Langgar ini merupakan tempat sultan dan kerabatnya melaksanakan salat tarawih di bulan suci Ramadhan dan sebagai tempat pembacaan naskah Isra Mi'raj, Nisfu Sya'ban, dan lain-lain.

\section{PENUTUP}

Berdasarkan titimangsa yang ditulis di Pintu Jinem, Keraton Kanoman dibangun pada tahun 1510 Saka atau 1588 M. Tahun Titimangsa tersebut bergambar "matahari" berarti 1, "wayang darma kusuma" berarti 5, "bumi" berarti 1, dan "binatang kamangmang" yang berarti 0 , apabila digabungkan menjadi 1510 . Keraton Kanoman dibangun setelah Keraton Pakungwati terjadi kekosongan kekuasaan. Adanya kekosongan kekuasaan terjadi disebabkan Pangeran Girilaya beserta kedua puteranya berad di Mataram. Setelah ada berita Pangeran Girilaya meninggal dunia di Mataram, kedua puteranya masih ditahan di Mataram. Setelah mendapat bantuan dari sultan Banten, mereka dibebaskan oleh Trunojoyo, kemudian dibawa ke Banten. Oleh sultan Banten, kedua putera Pangeran Girilaya dibawa ke Cirebon, kedua putera Girilaya tersebut dianggap mempunyai kedudukan yang sama untuk memimpin Keraton Cirebon. Pangeran Martawijaya menjadi sultan sepuh dan Pangeran Kartawijaya menjadi sultan anom dengan sebutan Pangeran Badrudin. Sultan Badrudin pada saat menjabat sebagai sultan anom membangun Keraton Kanoman menghadap ke utara dengan alasan magnet bumi menghadap ke utara.

Cirebon yang dirintis oleh Sunan Gunung Jati, dijadikan sebagai pusat penyebaran agama Islam untuk wilayah Cirebon dan sekitarnya. Dampak dari kegiatan yang dilakukan Sunan Gunung Jati tersebut terlihat pada beberapa bangunan yang ada di Keraton Kanoman, Bangsal Jinem misalnya. Pendopo ini disangga dengan lima pasang tiang besar, melambangkan shalat lima waktu, juga disangga dengan dua puluh tiang kecil 
melambangkan sifat-sifat Allah yang berjumlah 20. Ia juga membangun beberapa bangunan, yang difungsikan sebagai tempat tinggal sultan dan keluarga, tempat pertemuan, tempat menyimpan benda-benda pusaka, Langgar Alit, Siti Inggil, dan bangunan lainnya. Sebagian bangunan yang ada mengandung simbol yang berkaitan dengan ajaran Islam. Simbol-simbol tersebut menandakan bahwa Keraton Pakungwati dahulunya dijadikan tempat penyebaran agama Islam yang dibawakan oleh Sunan Gunung Jati, pendiri Kasultanan Cirebon.

Cirebon yang dijadikan basis penyebaran agama Islam oleh Sunan Gunung Jati masih dilestarikan oleh keturunannya. Salah satu di antaranya Keraton Kanoman masih melakukan kegiatan upacara panjang jimat sebagai salah satu upaya mengingat akan kelahiran Nabi Besar Muhammad SAW. Upacara adat yang dilaksanakan oleh Keraton Kanoman merupakan aset sejarah dan budaya yang dimiliki pemerintah setempat, sehingga bisa dijadikan sebagai objek wisata dan budaya. Selain itu kegiatan yang dilakukan oleh pihak Keraton Kanoman juga sebagai bentuk pelestarian budaya, seperti melakukan peringatan 1 Muharam yang dijadikan sebagai cikal bakal lahirnya Cirebon yang jatuh tanggal 1 Muharam, kegiatan yang dilaksanakan satu tahun sekali tersebut mengambil tempat di Bangsal Witana.

\section{DAFTAR SUMBER}

\section{Buku}

Asmar, Teguh, 1975.

Sejarah Jawa Barat, dari PraSejarah hingga Masa Penyebaran Agama Islam. Bandung: Proyek Penunjang Peningkatan Kebudayaan Nasional Provinsi Jawa Barat.

Atja, 1972.

Tjarita Purwaka Caruban Nagari. Sedjarah Muladjadi Tjirebon. Jakarta: Ikatan Karyawan Museum.
Danasasmita, Saleh et al., 1983/1984

Rintisan Penelusuran Masa Silam, Sejarah Jawa Barat, Jilid IV. Bandung: Proyek Penerbitan Sejarah Jawa Barat, Pemerintah Provinsi Daerah Tingkat I.

Daldjoeni, 1986

Geografi Kota dan Desa. Bandung: Alumni.

Effendi, Khasan, 1994.

Pertalian Keluarga Raja-raja Jawa Kulon dengan Keraton Pakungwati, Sunan Gunung Jati Muara Terakhir Keluarga Raja-Raja Jawa Kulon. Bandung: Indra Prahasta.

Hadidjah, et $\underline{\text { al }}, 2006$.

$\begin{array}{lcr}\text { Potensi } & \text { Wisata Budaya Kota } \\ \text { Cirebon. } & \text { Cirebon: } & \text { Dinas }\end{array}$

Kebudayaan dan Pariwisata.

Hadisiswaya. 2009.

Keraton Undercover, Penyingkiran

Putera Mahkota Asli dalam Perebutan Tahta Keraton Solo. Yogyakarta: Pinus Book Publisher.

Kunto, Haryoto. 1992/1993.

Riwayat Kota di Tatar Sunda. Bandung: Kerja sama BappedaHexagon.

Iskandar, Yoseph. 1997.

Sejarah Jawa Barat, Yuganing Rajakawasa. Bandung: Geger Sunten. , et al., 2000.

Negara Gheng Islam Pakungwati Cirebon. Bandung: Padepokan Sapta Rengga Banjaran.

Lubis, Nina Herlina, et.al. 2003.

Sejarah Tatar Sunda, Jilid 1. Bandung: Satya Historika. 
Radjiman. 1984.

Sejarah Mataram Kartasura sampai Surakarta Hadiningrat. Solo: Krida.

Rochani, Ahmad Hamam. 2008.

Babad Cirebon. Cirebon: Dinas

Kebudayaan dan Pariwisata Kota Cirebon.

Salana. 1987.

Sejarah Carbon, Jilid 1. Cirebon: tanpa penerbit.

Santosa, F. Harianto, 2003

Profil Daerah Kabupaten dan Kota, cetakan ke II. Jakarta: Kompas.

Soeratman, Darsiti, 1994

Kehidupan Dunia Keraton Surakarta 1830-1939. Yogyakarta: Yayasan Untuk Indonesia.

Sujana, 1996

Pelabuhan Cirebon Dahulu dan

Sekarang. Makalah Diskusi Ilmiah Cirebon sebagai Bandar Jalur Sutra. Jakarta: Departemen Pendidikan dan Kebudayaan.

Sunardjo, Unang, 1983

Meninjau Sepintas Panggung

Sejarah Pemerintahan, Kerajaan

Cerbon, 1479-1809. Bandung:

Tarsito.

Suyitno, Anang. 1991.

Bunga Rampai Jawa Barat.

Bandung: Yayasan Wahana Citra

Nusantara.

Tim Peneliti Jurusan Sejarah Fak. Sastra Unpad, 1991.

Sejarah Cirebon Abad Ketujuh Belas. Bandung: Pemda Tk I Prov. Jabar bekerja sama dengan Fak. Sastra Unpad.

Yayasan Mitra Budaya Indonesia. 1982.

Cerbon. Jakarta: Sinar Harapan.

\section{Internet}

"Keraton Kanoman" dalam http://www.disparbud.jabarprov.go.i $\underline{\mathrm{d}}$, diakses: tanggal 10 September 2012 jam 11.05

"Mengenang Cirebon lewat malam 1 Syuro" dalam http://news.okezone.com, diakses: tanggal 10 September 2012 jam 19.15

"Wulan Sapar (Saparan)" dalam http://carubannagari.blogspot.com, diakses: tanggal 10 Oktober 2012 jam 11.55

"ritual penyucian gamelan sekati" dalam

http://kesultanankanoman.blogspot.c om, diakses : 23 September 2012

"keraton kanoman gelar tradisi grebeg syawal" dalam http://www.cirebonkota.go.id), diakses : 24 September 2012

\section{Informan}

Nama : Chepy

Jabatan : Humas Keraton Kanoman

Usia : 45 tahun

Nama : Ratu Arimbi

Jabatan : Sekretaris Keraton Kanoman

Usia : 42 tahun

Nama : Elang Suhardja

Jabatan : Pemandu Keraton Kanoman

Usia : 46 tahun 